\title{
Article
}

\section{Promoting mental health and wellbeing in practice}

Keeling, Joanne and McQuarrie, Catherine

Available at http://clok.uclan.ac.uk/23391/

Keeling, Joanne ORCID: 0000-0002-0151-7234 and McQuarrie, Catherine (2014) Promoting mental health and wellbeing in practice. Mental Health Practice, 17 (5). pp. 26-28. ISSN 1465-8720

It is advisable to refer to the publisher's version if you intend to cite from the work. http://dx.doi.org/10.7748/mhp2014.02.17.5.26.e873

For more information about UCLan's research in this area go to

http://www.uclan.ac.uk/researchgroups/ and search for <name of research Group>.

For information about Research generally at UCLan please go to http://www.uclan.ac.uk/research/

All outputs in CLoK are protected by Intellectual Property Rights law, including Copyright law. Copyright, IPR and Moral Rights for the works on this site are retained by the individual authors and/or other copyright owners. Terms and conditions for use of this material are defined in the policies page.

\section{CLoK}

Central Lancashire online Knowledge www.clok.uclan.ac.uk

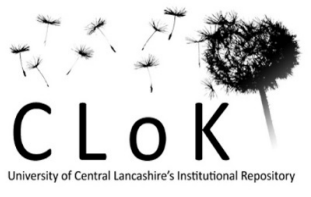




\section{Mental Health Practice \\ Promoting Mental Health and Well-being in Practice - A Working Model. --Manuscript Draft--}

\begin{tabular}{|c|c|}
\hline Manuscript Number: & MHP873R1 \\
\hline Full Title: & Promoting Mental Health and Well-being in Practice - A Working Model. \\
\hline Corresponding Author: & $\begin{array}{l}\text { Joanne L Keeling } \\
\text { School of Nursing University of Salford Peel House Eccles Manchester } \\
\text { UNITED KINGDOM }\end{array}$ \\
\hline Abstract: & $\begin{array}{l}\text { Literature on mental health promotion and well-being stresses the importance of } \\
\text { inherent key concepts such as empowerment, collaboration and recovery and indicates } \\
\text { that the delivery of intervention or the process of implementation is just as important as } \\
\text { the content. This article presents a model that embeds the key concepts inherent } \\
\text { within mental health and well-being promotion into a working framework: it may be } \\
\text { useful for practitioners working within a variety of settings both as a guide for } \\
\text { meaningful intervention and as a self development tool. }\end{array}$ \\
\hline \multicolumn{2}{|l|}{ Additional Information: } \\
\hline Question & Response \\
\hline $\begin{array}{l}\text { Please confirm that you have read and } \\
\text { agree to our Publisher's Agreement that is } \\
\text { available here }\end{array}$ & Yes \\
\hline $\begin{array}{l}\text { Have you submitted this manuscript } \\
\text { elsewhere? }\end{array}$ & No \\
\hline $\begin{array}{l}\text { Has this manuscript already been } \\
\text { published? }\end{array}$ & No \\
\hline $\begin{array}{l}\text { What is the word count of your document } \\
\text { excluding both references and the } \\
\text { abstract? }\end{array}$ & 1986 \\
\hline Author Comments: & $\begin{array}{l}\text { Thank you for the helpful feedback for this submission. I have amended the } \\
\text { submission to include the following in response to the reviewers comments: } \\
\text { Origins and development of the model have been made explicit. Theoretical } \\
\text { underpinnings have been strengthened. Feedback from students and conference } \\
\text { participants have been added to strengthen the rationale and development/need of the } \\
\text { model. }\end{array}$ \\
\hline
\end{tabular}


"I understand the concepts involved within mental health and wellbeing promotion but how do I do it in practice?" This was a commonly asked question by student mental health nurses when teaching an undergraduate module in mental health promotion. The ideal answer to have given would have been to say, "go and see how they do it in practice" but unfortunately, as much mental health promotion implementation work may be hidden or difficult to recognise in practice (Owens et al, 2010), especially for the inexperienced eye, this response fell somewhat short of answering the question posed by the students. With this in mind, a look at the evidence of mental health and well-being promotion activities in practice showed much commentary in the literature on initiatives that have been developed; most focusing upon social inclusion and community engagement that were setting specific in terms of target audience (Dyer and Mills, 2011; Skingley and Bungay, 2011). Additionally, there have been some generic templates for putting mental health promotion into action as suggested by Barry and Jenkins (2007). Thus in response to the initial question posed by students we have developed what we consider to be a universal model in terms of its utility both as a self development framework and a model for implementing mental health and well-being promotion in practice. The model was developed initially in an attempt to offer a clearer way of working for students to be able to "see" the principles of mental health and well-being promotion in practice. However, we now consider that the model may be universal in its application: both as a guide to meaningful intervention and as a self development framework to support practitioners and learners in developing self efficacy (Bandura, 1977). In this respect the practitioner/learner may be better supported to make the transition from a supported practitioner to a creative practitioner.

The Promoting Mental Health and Wellbeing Working Model

The development of the model has been ongoing since 2009 being initially presented as a poster at the $15^{\text {th }}$ International Network for Psychiatric Nursing Research Conference (Keeling and McQuarrie, 2009). At this time the model existed as a framework for staff in statutory services and was borne from mentors and student mental health nurses experiences of working in these environments and having difficulty in recognising specific mental health promotional interventions due to the subtle nature of this work. Student evaluations of the framework indicated that it had been useful in providing a structured approach to working and had raised awareness of the different elements inherent within mental health promotion and how these elements interlinked. Students suggested that the framework could be applicable in other environments where mental health and well being promotion were integral to practice. Consequently, the framework was developed as a generic model and was presented at the Nordic Conference of Mental Health Nursing in Helsinki in 2010 (Keeling and McQuarrie, 2010). The model was well received by participants at the conference, whom were both from practice 
and academic settings, and informal evaluations proved useful in further development of the model to make explicit its potential utility as a Universal model having dual utility as both a model for working and a staff development tool.

In the following explanation of the working model we refer to the person with a remit to promote mental health and well-being as the practitioner and to the service user/client/patient as the individual in keeping with the inherent key concepts within the subject matter. The model has four components which are each based upon concepts inherent within the academic commentary on mental health and well-being promotion (Seymour and Gale, 2005; Cattan and Tilford, 2006; Barry and Jenkins, 2007). Collaborative working in identifying need indicates clearly that a partnership process is necessary in the initial contact with any individual. This part of the model requires the practitioner to create an environment in which the individual feels in control and is the director of identifying the things that he feels are most important to him. It is important to bear in mind here that an individual's goal may not be specific to a particular diagnosis: indeed many authors conclude that many activities most likely to be of benefit to a person's wellbeing have no stated or specified mental health goal (Herrman, Saxena and Moodie, 2005). This is in contrast to a more strategic or outcome orientated approach sometimes adopted by practitioners engaging with solution focused or brief intervention therapies (O'Connell, 2005). In identifying his own need the individual is encouraged to take ownership of the process of enhancing well-being. The role of the practitioner is to support, encourage and motivate the individual to take time to think about what aspect of his life he would like to enhance/change and to consider what the beneficial impacts of this change might be (Prochaska, DiClemente and Norcross 1992). This process can be supported by the use of motivational interviewing (Miller and Rollnick 2002) on the part of the practitioner and considering the explanation of the change theory to the individual. It is important to stress that a goal in the individual's life may be reached through a series of small steps; in this respect the small steps become the building blocks of enhancing well-being, not the goal in itself. This idea is based on the concept of recovery and the belief that hope and a joint approach between the individual and the practitioner in identifying need will ultimately bring about the best outcomes in terms of an individual's well-being. This is a shift from the traditional bio psychiatry model in which the practitioner "imposes knowledge" (Walsh et al, 2008) and identifies the need for the individual from an already established assessment tool. In this respect the starting point for this working model cannot be based upon any pressure to conform with a medical model or adopt prescriptive practises (Pearson ,2010). The model prompts the practitioner to draw upon skills of meaningful engagement, negotiation and listening to what the individual considers important in terms of his own well being. This draws upon a participatory wellbeing assessment approach in which the work is guided by the individual's perception of well-being and their definition of need (Cornwall et al, 2003). 
The next component of the model prompts the worker to consider engagement with statutory and non statutory services. This is considered important in an increasing fragmented society in which many services exist with a remit to promote well-being, but may not naturally liaise or work with each other. The ability of practitioners and individuals to draw upon wider support mechanisms is especially attractive in the current financial climate, in which practitioners are expected to provide care with fewer financial resources. It is important to have a knowledge and awareness of the services on offer from statutory and non statutory organisations in the local, wider and online community that could assist the individual in seeking to meet his identified need. It is envisaged here that a community of practice could be developed within local services in which networking and sharing of ideas and resources would strengthen communities (Letcher and Perlow, 2009). It is imperative here that the perception of a "community" incorporates not just traditional health services, but social support and lay groups often provided by voluntary and independent sector organisations or those that are established by people in the local community. Establishing partnerships between organisations and people has long been proven to be effective in terms of professional development and similarly in improved wellbeing outcomes for individuals (Cornwall et al, 2003). Paton, Sengupta and Hassan (2005) in the explanation of their Healthy Living and Working Model explain that an integration of approaches across stakeholders is essential to health promotion. Although a dialogue between services would be beneficial in achieving this, it is not always a given that services will have the same values and few constraints. Thus as a practitioner seeking to assist an individual to promote his well-being it is important to have an awareness of where, when and what different services offer and how he might encourage this dialogue through practice development approaches.

"Creativity in approach" is a crucial aspect of the working model in that it relies upon collaboration and an awareness of local services and is the "doing" part of the model often referred to as intervention. The ability of the practitioner and the individual to consider intervention that may exist outside traditional services seeks to encourage creativity in approach to addressing the perceived need. It is also important for the practitioner to maintain awareness that intervention may come from the individual himself. The role of the practitioner here is to facilitate the individual to harness already established personal coping mechanisms, hobbies and interests in enhancing his own well being. This is again is in keeping with a self efficacy and collaborative approach (de Silva, 2011).

Thus, rather than intervening in the individual's life, this part of the model enables the practitioner and individual to seek the approach or strategy that they feel would best meet the identified need. This is in contrast to the traditional working practice where the practitioner prescribes an activity/task to the individual. A knowledge of services available is useful here as the individual, using the model, may be beginning to develop a "toolkit" of wellbeing networks 
and organisations that may be of interest to the individual. However, harnessing the individual's own interests has merit here also, and there are many examples within the literature of using arts, sport and outdoor activities as a means to enhance well being. Whilst these activities are not traditional "prescribed interventions", increased social interaction, enjoyment and physical improvement have been measured as positive outcomes of engaging with these approaches (Skingley and Bungay 2010; Dyer and Mills, 2011; Allison, 2011).

Conducive and constraining factors to implementation is the final component of the model and assists with the appraisal and "realistic" evaluation of the well being promotion activity drawing a parallel to the theory based evaluation "theories of change" approach (Connell and Kubisch, 1998). Dooris (2005) explains this succinctly when he cites the stakeholders as explicit in participating in theory generation. In this respect, the model prompts the practitioner and individual to become part of their own evidence base in measuring effectiveness. The final component of the model aims at encouraging the individual and practitioner to discuss what factors assisted or will assist in the implementation of the strategies and which factors hindered or would prevent full implementation of the activity or strategy. This discussion is important as a learning tool for future work as some factors may remain constant (such as financial constraints or fluctuating motivation or confidence on the part of the individual) and some may be activity or strategy specific ("the group was not what I expected" or "I didn't like the activity"). This enables the need or the approach to be modified or changed and can allow for conducive factors to be perpetuated and constraining factors to be challenged.

\section{Conclusion}

This working model seeks to embed key principles of mental health and well being promotion into a tangible succinct model which can be used in multiple settings. Practitioners and learners can use the model as a self development tool and as a model to structure their own practice. Due to its simplicity, the model is not intended to be an academic proposal, but may provide a vehicle for achieving the best outcomes for individuals' mental health and well-being in many settings. Evaluations from student mental health nurses, practitioners and academics have proven to be positive in terms of the development of the model and in appraising the possible utility of the model. As a self development tool the model is intended to be shared amongst practitioners, learners and individuals so that they may begin to develop their own skills and resources in achieving the best outcomes according to the people with which they work.

\section{References}

Allison R (2011) Engaging clients through outdoor activites. Mental Health Practice 14,5,16-19. Bandura, A. (1977). Social Learning Theory. General Learning Press: New York. 
Barry MM and Jenkins R (2007) Implementing mental health promotion. Churchill Livingstone: London.

Cattan M and Tilford S (2006) Mental Health Promotion: A lifespan approach. Open University Press: Maidenhead.

Connell, J and Kubisch A (1998) Applying a theory of change approach to the evaluation of comprehensive community initiatives: progress, prospects and problems, in Fulbright-Anderson K , A Kubisch and J Connell (eds) New Approaches to Evaluating Community Initiatives, vol. 2, Theory, Measurement, and Analysis. Aspen Institute: Washington DC.

Cornwall A, Pawan L, Kennedy K and Owen F (2003) Putting partnership into practice: participatory wellbeing assessment on a south London housing estate. Health Expectations 6,30-43.

De Silva (2011) Evidence: helping people help themselves. The Health Foundation: London. Dooris M (2005) Healthy settings: challenges to generating evidence of effectiveness. Health Promotion International 21,1,55-65.

Dyer L and Mills C (2011) Service users are inspired to imagine their goals. Mental Health Practice 14,5,32-35.

Herrman H, Saxena S, Moodie R (eds) (2005) Promoting mental health: concepts, emerging evidence, practice. Geneva: WHO.

Keeling J and McQuarrie C (2009) From a supported practitioner to a creative practitioner: promoting wellbeing in practice: A framework for development for staff in statutory services. $15^{\text {th }}$ International Network for Psychiatric Nursing Research (NPNR) Conference 2009. Royal College of Nursing: Oxford.

Keeling J and McQuarrie C (2010) Promoting mental health in practice: A framework for staff development. Nordic Conference of Mental Health Nursing 2010. Finnish Nurses Association: Helsinki Finland.

Letcher AS and Perlow KM (2009) Community-based participatory research shows how a community initiative creates networks to improve well-being. American Journal of Preventative Medicine 37,6S1.

Miller WR and Rollnick S (2002) Motivational Interviewing: preparing people for change $2^{\text {nd }}$ edition. Guilford Press: London.

O'Connell B (2005) Solution-focused therapy $2^{\text {nd }}$ edition. Sage: London.

Owens C, Crone D, Kilgour L and El Ansari, W (2010) The place and promotion of well-being in mental health service: a qualitative investigation. Journal of Psychiatric and Mental Health Nursing 17,1-8.

Paton K, Sengupta S and Hassan L (2005) Settings, systems and organization development: the healthy living and working model. Health Promotion International 20,1,81-89.

Prochaska JO, DiClemente CC and Norcross JC (1992) In search of how people change: applications to addictive behaviours. American Psychologist 47,9,1102-1114. 
Pearson GS (2010) Keeping mental health promotion alive. Perspectives in Psychiatric Care $46,1,1-2$.

Seymour L and Gale E (2005) Mental health and mental health promotion in Ewles L (ed) Key Topics in Public Health. Elsevier: London.

Skingley A and Bungay $\mathrm{H}$ (2010) The silver song club project: simging to promote the health of older people. British Journal of Community Nursing 15,3,135-140.

Walsh J, Stevenson C, Cutcliffe J and Zinck K (2008) Creating a space for recovery-focused psychiatric nursing care. Nursing Inquiry 15,3,251-259. 


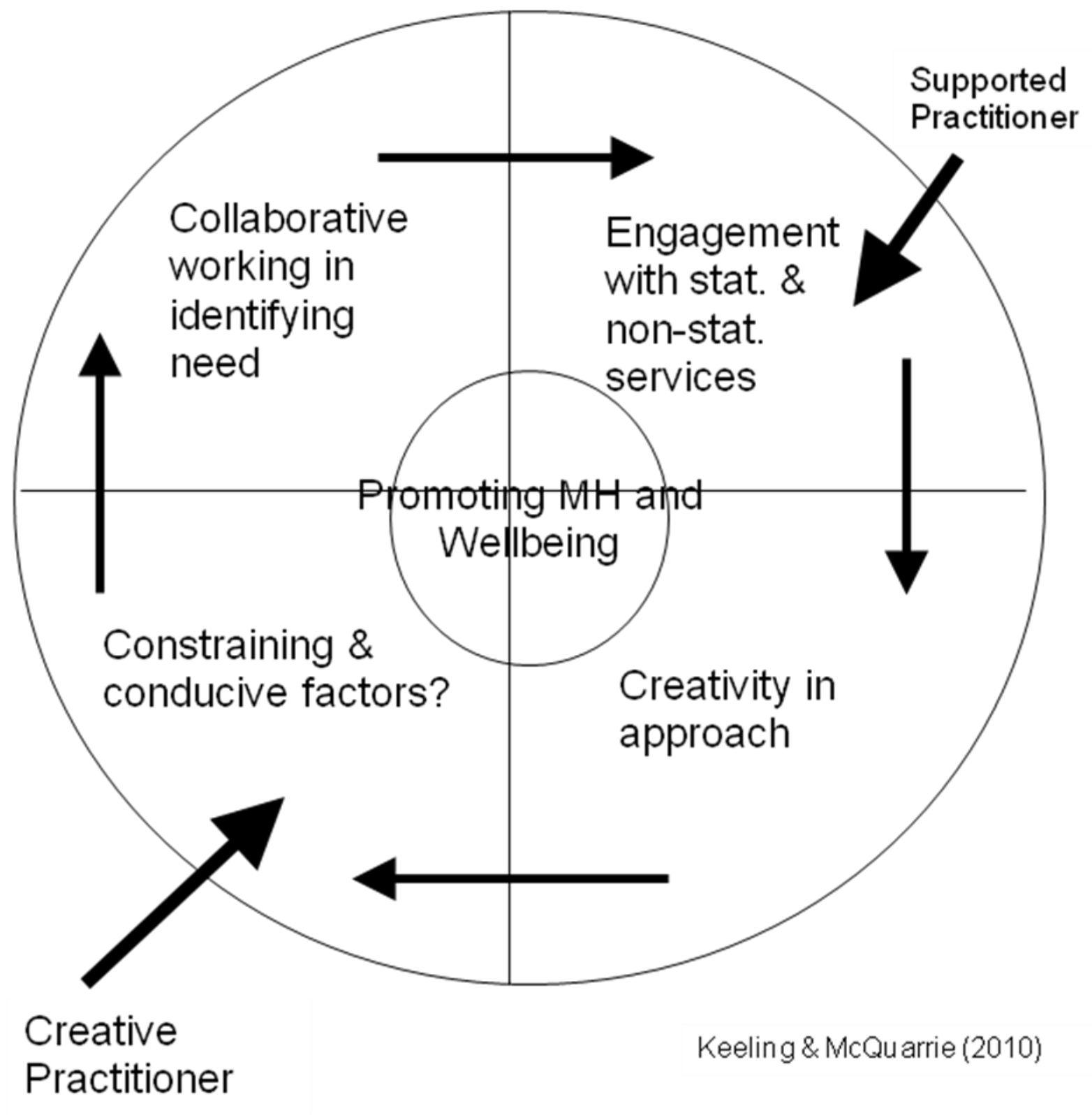

Figure 1.

Promoting Mental Health andWellbeing in Practice-A Working Model. 